\title{
Metal Oxide Semiconductor: Future Material for Gas Sensors and it's Synthesis Techniques
}

\author{
Binita Nanda, Snehashis Panda, Farida A. Ali
}

\begin{abstract}
This paper provides a complete idea about metal oxide semiconductors ((MOSs) for gas sensing application. Metal oxide semiconductor nano-materials are showing much higher strength in many industries, research laboratories and public health and so on with their effective chemical, physical, and electronic properties. The morphology, band gap, porosity, conductivity properties, low cost and high surface area etc. are few of the properties of MOSs that are responsible for the enhancement of sensing properties in various applications. Besides these, now-a-days MOSs are grown in different nanostructures like nano rods, nano flowers, nano sheets, nanowires etc. using the various growth techniques which are further responsible for their betterment as gas sensors. Therefore, this paper gives a complete idea about the different methods of synthesis of MOSs.
\end{abstract}

\section{INTRODUCTION}

Sensor seems to have come from the word 'sense' means to detect external stimulus. Hence, a sensor is a device that receives a signal of any form like physical or chemical or biological and converts it into an equivalent electric signal that should be compatible with electronic circuits [1]. Sensitivity is the ratio of magnitude of output signal to the magnitude of input signal. Sensor units with lower maintenance, higher reliability, lower cost, lower weight and less complex system architecture are highly needed. Till date different types of sensors have been developed by the researchers for different types of physical properties such as: speed [2], temperature [3], pressure [4], humidity [5], Infrared [6], gas [7] etc. for energy saving as well as for protection from different kinds of hazards. Amongst all, gas sensing technology has received increasing attention and has become more significant because of its widespread and common applications basing on their detecting and monitoring capability of flammable, toxic and exhaust gases both in domestic as well as in industrial environment. Apart from commercial use of gas sensors, indoor air quality monitoring is of great importance.

The detection of gas molecules such as triethyl amine [8], $\mathrm{CO}$ [9], formaldehyde [10], $\mathrm{NO}_{\mathrm{x}}$ [11], $\mathrm{H}_{2}$ gas [12] etc. are highly necessary due to their toxicity and associated risk to the ecosystem. Gas sensors with greater selectivity and higher sensitivity are on demand, for which many efforts are being made by the researchers for the selection of better gas sensing materials. In order to achieve an outstanding

Revised Manuscript Received on 14 August, 2019.

Dr. Binita Nanda, Assistant Professor, Electronics and Instrumentation Engineering at Sikhsha 'O' Anusandhan (Deemed to be) University, Bhubaneswar, Odisha, India.

Subashis Panda, Assistant Professor, Electronics and Instrumentation Engineering, Sikhsha 'O' Anusandhan (Deemed to be) University, Bhubaneswar, Odisha, India.

Dr. Farida A. Ali, Assistant Professor, Electronics and Instrumentation Engineering at Sikhsha ' $O$ ' Anusandhan (Deemed to be) University, Bhubaneswar, Odisha, India. performance in gas sensing application a number of sensing materials such as metal oxide semiconductors (MOSs) [13], polymers [14], carbon nano tubes [15], graphene materials [16] have been taken a great interest. Among the different kinds of sensing materials MOSs are most investigated gas sensors having size in the range of 1-100 $\mathrm{nm}$. These semiconducting materials show their uniqueness because of their mechanical, optical, electrical, magnetic and catalytic properties [17]. Apart from these properties, materials used for gas sensors need to show high surface area, so that significant resistant change may take place when exposed to target gases. Larger surface area increases the surface to volume ratio of the material leading to more adsorption of the target gas at the reaction sites and therefore a large resistance change takes place leading to better sensitivity [18]. In addition to high sensitivity, faster responserecovery, long term stability, excellent selectivity and most importantly cost effectiveness of MOSs places them at the top of the list as far as gas sensing applications are of concern. Apart from the surface area, other two most important factors responsible for sensing are i) morphology (size, shape and geometry) of the material ii) electron $\left(\mathrm{e}^{-}\right) /$ hole $\left(\mathrm{h}^{+}\right)$transportation in MOSs. Good crystalline structure, ability of doping noble metal and high production rate has increased the production of MOS based gas sensors [19].

To get proper structure and morphology of MOSs, synthesis plays an important role in material science. Among different synthesis methods thin film perform a significant part in sensing. The thicknesses of thin films are typically less than several microns and formed by atom to atom or molecule to molecule condensation [20]. In this article, we focused different synthetic procedure to develop thin film MOSs towards sensing.

\section{METHOD OF SYNTHESIS}

Metal oxide semiconductors for gas sensing application can be synthesized by various techniques like Spray pyrolysis technique, Physical vapor deposition (PVD) technique, Chemical vapor deposition (CVD) technique, Spin coating technique. Fabrication of gas sensors by depositing the material like a thin film over any substrate using the above techniques are possible.

\section{Physical Vapor Deposition (Pvd) Technique}

Sputtering is a physical vapour deposition (PVD) technique used to deposit the material in the form of a thin film onto a surface as shown in Fig 1 below. In this process first of all gaseous plasma is created which consists of ions,

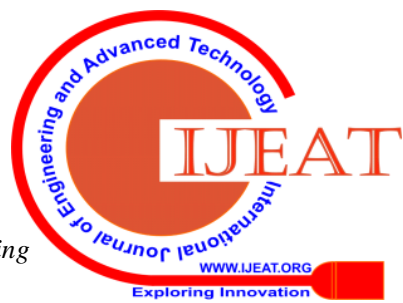


which are then accelerated from the plasma into the other source material. High velocity positive ions (argon plasma) are directed towards the target surface to bombard and due to their momentum transfer process between the sputter gas and target atoms ejection from the surface or source atoms takes place. The ejected atoms from the target condense on the substrate to form a film.

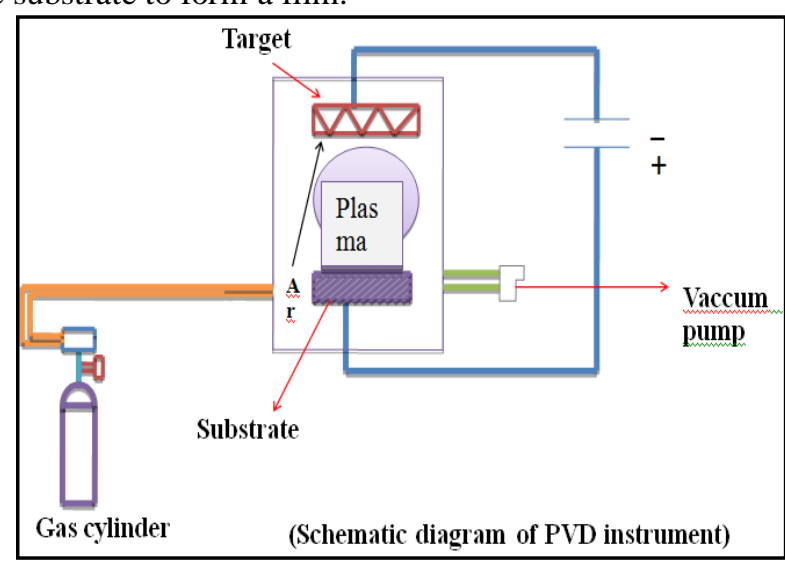

Fig 1. Schematic diagram of PVD technique

Besides neutral atoms, charged atoms and electrons are also emitted from the target surface and the number of atoms ejected per incident ion, which is termed as sputtering yield (S). Sputtering yield depends on various parameters like the composition of the material, binding energy, experimental geometry and the characteristics of the incident ion. Besides the mentioned parameters it is also dependent on the voltage and current at which sputtering takes place, which is because sputtering is done either using DC voltage (DC Sputtering) or using AC voltage (RF Sputtering). In case of DC sputtering, voltage is set from 3 to $5 \mathrm{KV}$, whereas for the RF sputtering a high voltage RF power supply is used set at $14 \mathrm{MHz}$. Sputtering is one of the preferred ways for deposition on a larger surface area not only due to high uniformity, density and lesser interface roughness of the deposited film, but also due to the higher kinetic energy of the sputtered particles which gives better adhesion to the substrate. A. Sanger and his co-workers have used the sputtering method to deposit a vertically aligned, highly ordered $\mathrm{Pd}$ decorated $\mathrm{MnO}_{2}$ nanowall directly on a porous anodic alumina (AAO) and later used it as a gas sensor [21]. J. Zeng and his team used anodic oxidation method on DC magnetron sputtered metallic tungsten (W) film deposited on alumina substrate to synthesize high surface area porous $\mathrm{WO}_{3}$. The gas sensing properties of porous $\mathrm{WO}_{3}$ has been checked for $\mathrm{NO}_{2}$ gas and found to be ranging from $100 \mathrm{ppb}$ to $5 \mathrm{ppm}$ for an operating temperature after annealing with the grain size of the $9 \mathrm{~nm}\left(\mathrm{WO}_{3}\right.$ particle). High response has been reported towards sensing activities of $\mathrm{NO}_{2}$ of different concentrations due to larger surface area, smaller grain size [22]. E. Turgut and his coworkers were grown $\mathrm{NiO}$ thin films by $\mathrm{RF}$ magnetron sputtering under different oxygen partial pressure by taking pure $\mathrm{Ni}$ as target. Surface morphology and crystalline structure is hugely dependent upon the oxygen partial pressure effect. The granule size is $70 \mathrm{~nm}$ when the sample is grown on the moderate $\mathrm{O}_{2}$ partial pressure whereas the granule size is reduced to $50 \mathrm{~nm}$ at higher partial pressure $100^{\circ} \mathrm{C}$ to $200^{\circ} \mathrm{C}$. The SEM confirmed a coral like structure

[23]. Behera et al. used sputtering technique to deposit a 100 nm thickness Tungsten metal film on $\mathrm{SiO}_{2}$ coated $\mathrm{Si}$ substrate. Later to synthesize $\mathrm{WO}_{3}$ nano-rods, the obtained film was oxidized in atmospheric condition inside a horizontal tube furnace at $500^{\circ} \mathrm{C}$ for 4 hours. A chemiresistive type gas sensor was fabricated by using these nano-rods. The sensor was tested for different types of gases and it showed high sensitivity towards $\mathrm{NO}_{2}$ gases [24]. Vanadium pentoxidenano-needles for acetone sensor were synthesized by PVD method by Hakim et.al. Sensors sensitivity was tested by taking the acetone, ammonia, ethanol, propylamine at room temperature of concentration range 8.63-140 ppm and it showed better selectivity towards acetone gases [25]. Wei et.al have synthesized hollow porous flower like $\mathrm{In}_{2} \mathrm{O}_{3}$ for gas sensor application. The selectivity data of sensor reveals that at $500 \mathrm{ppb}$ concentration $\mathrm{NO}_{2}$ gas showed best result [26].

\section{Chemical Vapor Deposition Technique}

Coatings, powders, fibres and monolithic components can be fabricated by a versatile process called chemical vapour deposition (CVD). Using CVD technique it is possible to produce metals and nanometallic elements such as carbon and silicon as well as carbides, nitrides, oxides, inter metallics. Besides these CVD technique is also used in the manufacturing of semiconductors and other electronic components. The coating materials are mainly used in many optical, sensors, optoelectronic and corrosion applications. In chemical vapour deposition technique vapour transfer processes takes place at atomic level that is the deposition species are atoms or molecules or combination of all of these. It is not restricted to a line of slight deposition and has high throwing power. For three-dimensional configurations coating can be done with relative ease by this method at a higher deposition rate and thick coatings can be readily obtained. For CVD technique as shown in Fig. 2, ultrahigh vacuum is not necessarily required and the CVD equipments generally can adapt many process variations.

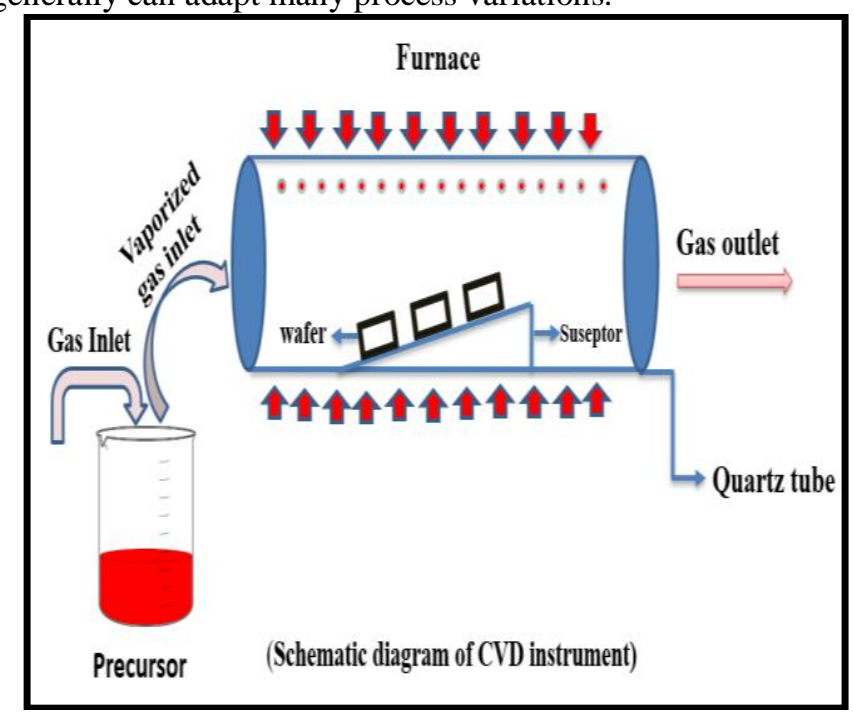

Fig 2. Schematic diagram of CVD technique

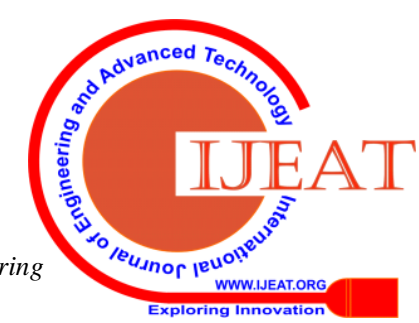


It is flexible enough that during deposition and codeposition of elements or compounds, many changes in composition is readily allowed and achieved too. $\mathrm{T}$. Stoycheva and his co-workers prepared micromachined gas sensors by integrating tungsten oxide nanostructures (NSs) in the form of polycrystalline films, non-aligned and quasialigned nanoneedles (NNs) films with aerosol assisted chemical vapour deposition (AACVD). They have been evaluated basing on their performance when used for various types of sensors like $\mathrm{NO}_{2}, \mathrm{EtOH}, \mathrm{H}_{2}, \mathrm{H}_{2} \mathrm{~S}, \mathrm{C}_{6} \mathrm{H}_{6}$ and $\mathrm{CO}$. For all the gasesnon-alligned $\mathrm{NN}$ sensors showed higher rate of response and high sensor activities compared to quasi-aligned NNs and polycrystalline films [27]. Januszko et al. established a thermoelastochromic sensor by preparing grapheme through chemical vapour deposition technique on copper and $\mathrm{SiO}_{2}$ substrate. The device exhibited high resistivity at increased temperature and it can be widely used in military and civil monitoring process [28].Arun et.al. synthesizedNiO/graphenenanocomposites for electrochemical non-enzymatic biosensor by CVD technique. The sensor showed high sensitivity towards cholesterol concentration ranges from $2 \mu \mathrm{M}$ to $40 \mu \mathrm{M}$ and also able to detect in low concentration range [29]. Room temperature $\mathrm{NO}_{2}$ gas sensor was fabricated by Shufen et.al. by taking $\mathrm{MoS}_{2}$ /porous silicon nanowires by different processes. The sensitivity of $\mathrm{NO}_{2}$ gases in different composites was tested [30]

\section{Flame Spray Pyrolysis Method (FSP)}

Nanostructured powdered material of a broad range with specific surface area and definite particle size in the range of few nanometers can be produced by a gas phase combustion synthesis method called Flame spray pyrolysis (FSP). FSP involves an exothermic combustion reaction of a metal organic liquid precursor. For the flame synthesis process, the metal organic liquid precursor in its homogenous phase is injected into the flame either through an evaporation system working under controlled temperature, or in liquid phase it is injected through a spray system. The main advantage of FSP is the use of a wide variety of possible low-cost precursors for obtaining nanostructured powdered material as a final product with high purity, relatively narrow size distribution and of particular morphology. N. Tammanoon et al. used the FSP method to synthesize $\mathrm{La}_{2} \mathrm{O}_{3}$-doped $\mathrm{SnO}_{2}$ nano particulate thick films for acetone sensor. $\mathrm{La}-\mathrm{SnO}_{2}$ nano belts were synthesized by thermal evaporation method. It exhibited optimal sensor responses to $100 \mathrm{ppm}$ acetone, $100 \mathrm{ppm}$ ethanol and $100 \mathrm{ppm}$ ethanediol of $2.28,3.75$ and 8.76 , respectively at $230^{\circ} \mathrm{C}$. $\mathrm{La}_{2} \mathrm{O}_{3}$ doping has primarily enhanced the acetone response due to the formation of $\mathrm{La}_{2} \mathrm{O}_{3}-\mathrm{SnO}_{2}$ heterojunction. Therefore, for acetone detection the FSP-made $\mathrm{La}_{2} \mathrm{O}_{3}$-doped $\mathrm{SnO}_{2}$ sensors are one of the potential devices with fast responsivity feature [31]. V. V. Ganbavleet. al. synthesized $\mathrm{Zn}_{2} \mathrm{SnO}_{4}$ thin films by FSP for $\mathrm{NO}_{2}$ gas sensors at moderate operating temperature. To obtain the $\mathrm{Zn}_{2} \mathrm{SnO}_{4}$ thin films, $\mathrm{ZnCl}_{2}$ and $\mathrm{SnCl}_{4}$ of required quantity were dissolved in $50 \mathrm{ml}$ of 2propanol to form $0.1 \mathrm{M}$ solution so that $\mathrm{Zn} / \mathrm{Sn}$ ratio can be maintained to $2: 1$. The precursor solution formed is then sprayed onto the preheated glass substrates at different temperatures ranging from 325 to $400^{\circ} \mathrm{C}$. The ternary oxide
$\mathrm{Zn}_{2} \mathrm{SnO}_{4}$ films deposited on glass substrate was then used for $\mathrm{NO}_{2}$ sensor. The films were very highly sensitive and selective towards $\mathrm{NO}_{2}$ gas. This indicates the sensitivity, fast response, stability and durability of the spray deposited $\mathrm{Zn}_{2} \mathrm{SnO}_{4}$ films [32].Nisha et.al. have synthesized $\mathrm{ZnO}$ thin films by spray pyrolys is technique using zinc acetate as the precursor dissolved in propanol and water. The sensor was tested for $\mathrm{NO}_{2}$ and $\mathrm{H}_{2} \mathrm{~S}$ gas and it showed better selectivity and response towards $\mathrm{NO}_{2}$ gas. At $200^{\circ} \mathrm{C}$ the sensors response for $7 \mathrm{ppm} \mathrm{NO}_{2}$ and $18 \mathrm{ppm}_{2} \mathrm{~S}$ gas were found to be 3.32 and 1.4 respectively [33]. Kim et. al. synthesized $\mathrm{CoCr}_{2} \mathrm{O}_{4}-\mathrm{Cr}_{2} \mathrm{O}_{3}$ heterojunctions by spray pyrolysis technique for xylene sensor. The sensors response to $\mathrm{p}$-xylene was studied by compairing the sensitivity of individual oxides with mixed hetero oxides and better resultswere found for hetero based mixed oxides [34]. Dan et. al. synthesized ZnOnanorods decorated with NiOnanosheets on FTO substrates by spray pyrolysis technique and observed the gas response of ethanol gas. The results showed $80 \%$ sensitivity towards $100 \mathrm{ppm}$ ethanol at operating temperature $200^{\circ} \mathrm{C}$ [35].

\section{Spin Coating Technique}

In case of a spin coating technique, there exist a solvent dispense system which dispenses the coating material onto the substrate surface and then a drying step which removes excess solvent from the substrate by controlling the spin speed and spin time. The thickness of the film depends not only on the spin speed and spin time but also on the viscosity and concentration of the solution and the solvent. Thus, to fabricate functional oxide layers on glass or single crystal substrates a small amount of coating material is dropped at the centre of a substrate which is either spinning at low speed or not spinning at all. Then the substrate is rotated at a higher speed so that due to the centrifugal force the coating material spreads throughout the substrate to form uniform thin films with nanoscale thickness. Samiksha et.al.have synthesized $\mathrm{MnO}_{2}-\mathrm{CoO}$ for humidity sensor using metal carboxylates as the precursors. For uniform deposition of $\mathrm{MnO}_{2}-\mathrm{CoO}$ thin film on flat borosilicate substrates spin coating technique is applied and then annealed at $650^{\circ} \mathrm{C}$. The humidity sensor was fabricated by using the film and the average sensitivity was found to be $2.225 \mu \mathrm{W} / \% \mathrm{RH}$ along with the response and recovery times $47 \mathrm{~s}$ and $59 \mathrm{~s}$ respectively [36]. Kim et. al. fabricated gas sensor for $\mathrm{H}_{2} \mathrm{~S}$ gas sensor by synthesizing $\mathrm{Fe}_{2} \mathrm{O}_{3}$ nanoparticles-decorated carbon nanotubes. The sensor showed high sensitivity and selectivity to $\mathrm{H}_{2} \mathrm{~S}$ gas at room temperature and found to be a promising material in environmental monitoring. Low ppm concentration of gases can also be detected by the sensor device [37].

\section{CONCLUSION}

The detection and monitoring of harmful toxic gases liberated from industries like power generation, automotive, ceramics, glass, petroleum is necessary for environmental concern. In this regard, gas sensors have taken greater

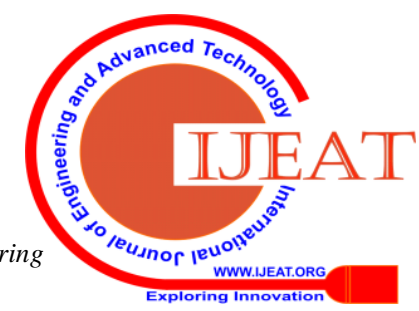


demand in environmental monitoring, automotive emission monitoring, domestic monitoring and food safety testing because of their low operating cost, cheap, reliable, low power consuming, improved energy efficiency and reduced emission. It is an attempt to study the MOSs for different gas sensors in the review. Two overall research trends are used in sensing mechanism are 1) there should be good correlation between sensing elements and sensing properties. 2) The new and improved material synthesis, novel synthetic procedure and combination of sensing technologies and advanced device fabrication are essential to improve the sensitivity and selectivity of gas sensors.

\section{REFERENCES}

1. Rossi A, Vila Y, Lusiani F, Barsotti L, Sani L, Ceccarelli $\mathrm{P}$, Lanzetta $\mathrm{M}$, Embedded smart sensor device in construction site machinery, Computers in Industry, 108 (2019), 12-20.

2. Park S J, Lee S H, Seol M L, Jeon S B, Bae H, Kim D, Cho G H, Choi Y K, Nano Energy, 55 (2019), 115-121.

3. Pan $\mathrm{T}$, Cao W, Wang $\mathrm{M}, \mathrm{TiO}_{2}$ thin film temperature sensor monitored by smartphone, Optical Fiber Technology, 45 (2018), 359-362.

4. Yenuganti S, Zhang H, Zhang C, Langasite crystal based pressure sensor with temperature compensation, Sensors and Actuators A: Physical, 281 (2018), 108-116.

5. Qi P, Zhang T, Shao J, Yang B, Fei T, Wang R, A QCM humidity sensor constructed by graphene quantum dots and chitosan composites, Sensors and Actuators A: Physical, 287 (2019), 93-101.

6. Bekhtin Y S, Babayan P V, Strotov V V, Onboard FPGA-based fast estimation of point object coordinates for linear IR-sensor, Microprocessors and Microsystems, 51 (2017), 99-105.

7. Sertel B C, Sonmez N A, Kaya M D, Ozcelik S, Development of $\mathrm{MgO}: \mathrm{TiO}_{2}$ thin films for gas sensor applications, Ceramics International, 45 (2019), 2917 2921.

8. Liu X, Zhao K, Sun X, Zhang C, Duan X, Hou P, Zhao G, Zhang S, Yang H, Cao R, Xu X, Rational design of sensitivity enhanced and stability improved TEA gas sensor assembled with Pd nanoparticles-functionalized $\mathrm{In}_{2} \mathrm{O}_{3}$ composites, Sensors and Actuators B: Chemical, 285 (2019), 1-10.

9. Haiduk Y S, Khort A A, Lapchuk N M, Savitsky A A, Study of $\mathrm{WO}_{3}-\mathrm{In}_{2} \mathrm{O}_{3}$ nanocomposites for highly sensitive $\mathrm{CO}$ and $\mathrm{NO}_{2}$ gas sensors, Journal of solid state chemistry, 273 (2019), 25-31.

10. Li G, Cheng Z, Xiang Q, Yan L, Wang X, Xu J, Bimetal $\mathrm{PdAu}$ decorated $\mathrm{SnO}_{2}$ nanosheets based gas sensor with temperature-dependent dual selectivity for detecting formaldehyde and acetone, Sensors and Actuators B: Chemical, 283 (2019), 590-601.

11. Yong Y, Cui H, Zhou Q, Su X, Kuang Y, Li X, Journal of physics and chemistry of solids, 127 (2019), 68-75.

12. Kumar M, Bhatt V, Kumar A, Yun J H, Nano lily-buds garden like $\mathrm{ZnO}$ nanostructures based gas sensor for $\mathrm{H}_{2}$ detection, Materials letters, 240 (2019), 13-16.

13. Offergeld M S, Hohe H P, Hackner M, Low Power High Speed CMOS Interface for MOS Gas Sensors, Procedia Engineering, 120 (2015), 1046-1049.

14. Diniz M O, Golin A F, Santos M C, Bianchi R F, Guerra E M, Improving performance of polymer-based ammonia gas sensor using POMA $/ \mathrm{V}_{2} \underline{\mathrm{O}}_{5}$ hybrid films, Organic Electronics, 67 (2019), 215-221.

15. Zandi A, Gilani A, Fard H G, Koohsorkhi J, An optimized resistive CNT-based gas sensor with anovelconfiguration by top electrical contact, Diamond and Related Materials, 93 (2019), 224-232.

16. Ayesh A I, Ahmed R E, Rashid M A, Alarrouqi R A, Saleh B, Abdulrehman T, Haik Y, Sulaiti L A, Selective gas sensors using graphene and CuOnanorods, Sensors and Actuators A: Physical, 283 (2018), 107-112.

17. Dey A, Semiconductor metal oxide gas sensors: A review, Semiconductor metal oxide gas sensors: A review, Materials science and engineering B, 229 (2018), 206-217.

18. Zhou X, Cheng X, Zhu Y, Elzatahry A A, Deng Y, Zhao D, Chinese Chemical Letters, 8417 (17), 30225-5.

19. Zappa D, Galstyan V, Kaur N, Sisman O, Comini E, AnalyticaChimicaActa, 2670 (18), 31089-4.

20. Meixner H, Gerblinger J, Lampe U, Fleischer M, Thinfilm gas sensors based on semiconducting metal oxides, Sensors and Actuators B: Chemical, 23 (1995), 119-125.

21. Sanger A, Kumar A, Chandra R, Kumar A, Highly sensitive and selective hydrogen gas sensor using sputtered grown Pd decorated $\mathrm{MnO}_{2}$ nanowalls, Sensors and Actuators B: Chemical, 234 (2016), 8-14.

22. Zeng J, Hu M, Wang $\mathrm{W}$, Chen $\mathrm{H}$, Qin $\mathrm{Y}, \mathrm{NO}_{2}$-sensing properties of porous $\mathrm{WO}_{3}$ gas sensor based on anodized sputtered tungsten thin film, Sensors and Actuators B: Chemical, 161 (2012), 447-452.

23. Turgut E, Coban O, Saritas S, Tuzemen S, Gur E, Oxygen partial pressure effects on the RF sputtered $\mathrm{p}$ type $\mathrm{NiO}$ hydrogen gas sensors, Applied surface science, 435 (2018), 880-885

24. Behera B, Chandra S, Synthesis of $\mathrm{WO}_{3}$ nanorods by thermal oxidation technique for $\mathrm{NO}_{2}$ gas sensing application, Materials science in semiconductor processing, 86 (2018), 79-84.

25. Hakim S A, Liu Y, Zakharova G S, Chen W, Synthesis of vanadium pentoxidenanoneedles by physical vapour deposition and their highly sensitive behavior towards acetone at room temperature, $R S C$ Advances, $[10.1039 / \mathrm{C} 4 \mathrm{RA} 16564 \mathrm{~K}]$.

26. Xu W, Li J, Sun J, Fabrication of monodispersed hollow flower-like porous $\operatorname{In}_{2} \mathrm{O}_{3}$ nanostructures and their application as gas sensors, RSC Advances,[10.1039/C5RA15832J].

27. Stoycheva T, Annanouch F E, Gracia I, Llobet E, Blackman C, Correig X, Micromachined gas sensors based on tungsten oxide nanoneedles directly integrated via aerosol assisted CVD, Sensors and Actuators B: Chemical, 198 (2014), 210-218.

28. Januszko A, Iwan A, Maleczek S, Przybyl W, Pasternak I, Krajewsak A, CVD-Graphene-Based Flexible, Thermo electrochromic Sensor, Journal of Nanomaterials, (2017), 1-8.

29. Rengaraj A K, Haldorai Y, Kwak C H, Ahn S, Jeon K J, Park S H, Han Y K, Huh Y S, Electrodeposition of flower-like nickel oxide on CVD-grown graphene to develop an electrochemical non-enzymatic biosensor, Journal of Materials Chemistry B, 3 (2015), 6301-6309.

30. Zhao S, Li Z, Wang G, Liao J, Lv S, Zhu Z, Highly enhanced response of $\mathrm{MoS}_{2}$ /porous silicon nanowire heterojunctions to $\mathrm{NO}_{2}$ at room temperature, RSC Advances, 8 (2018), 11070-11077.

31. Tammanoon N, Wisitsoraat A, Phokharatkul D, Tuantranont A, Phanichphant S, Yordsri V, Liewhiran C, Highly sensitive acetone sensors based on flame-spraymade La2O3-doped $\mathrm{SnO} 2$ nanoparticulate thick films, Sensors and Actuators B: Chemical, 262 (2018), 245262. 
32. Ganbavle V V, Patil M A, Deshmukh H P, Rajpure K Y, Development of $\mathrm{Zn}_{2} \mathrm{SnO}_{4}$ thin films deposited by spray pyrolysis method and their utility for $\mathrm{NO}_{2}$ gas sensors at moderate operating temperature,Journal of Analytical and Applied Pyrolysis, 107 (2014), 233-241.

33. Nisha $R$, Madhusoodanan $\mathrm{K} \mathrm{N}$, Vimalkumar $\mathrm{T} \mathrm{V}$, Vijaykumar $\mathrm{K} \quad \mathrm{P}$, Gas sensing application of nanocrystalline zinc oxide thin films prepared by spray pyrolysis,Bulletin of Materials Science, 38 (2015), 583591.

34. Kim B Y, Yoon J W, Lim K, Park S H, Yoon J W, Lee J $\mathrm{H}$, Hollow spheres of $\mathrm{CoCr}_{2} \mathrm{O}_{4}-\mathrm{Cr}_{2} \mathrm{O}_{3}$ mixed oxides with nanoscaleheterojunctions for exclusive detection of indoor xylene, Journal of Materials Chemistry C, 00 (2018) 1-3.

35. Li D, Zhang Y, Liu D, Yao S, Liu F, Wang B, Sun P, $\mathrm{GaO}$ Y, Chuai X, Lu G, CrystEngComm, 00 (2013), 1-3.

36. Sikarwar S, Yadav B C, Dzhardimalieva G I, Golubeva $\mathrm{N}$ D, Srivastava $\mathrm{P}$, Synthesis and characterization of nanostructured $\mathrm{MnO}_{2}-\mathrm{CoO}$ and its relevance as an optoelectronic humidity sensing device RSC Advances, 8 (2018), 20534-20542.

37. Kim W, Lee J S, Jang J, Facile synthesis of sizecontrolled $\quad \mathrm{Fe}_{2} \mathrm{O}_{3}$ nanoparticle-decorated carbon nanotubes for highly sensitive $\mathrm{H}_{2} \mathrm{~S}$ detection, $R S C$ Advances, 8 (2018), 31874-31880.

\section{AUTHORS PROFILE}

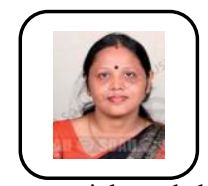

Dr. Binita Nanda is an Assistant Professor of Electronics and Instrumentation Engineering at Sikhsha 'O' Anusandhan (Deemed to be) University, where her research and teaching focus on metal modified mesoporous materials, functionalized mesoporous materials and their catalytic applications in catalytic and photo catalytic reactions.

Dr. Farida A. Ali is an Assistant Professor of Electronics and Instrumentation Engineering at Sikhsha 'O' Anusandhan (Deemed to be) University, where her research and teaching focus on solid state physics, characterization and simulation of classical and novel semiconductor devices including oxide semiconductors, thin films, DVLSI, Embedded systems and sensors $\mathrm{s}$.

Snehasis Panda is a M. Sc student working on designing of various metal oxide composites for different sensor applications. 